\title{
Modeling of sintering of moon soil imitators by solar radiation
}

\author{
A. V. Bagrov ${ }^{1}$, A. K. Sysoev², V.K. Sysoev ${ }^{1}$, A. D. Yudin ${ }^{1, \dagger}$ \\ †yudin@laspace.ru
}

\author{
${ }^{1}$ FSUE «LAVOCHKIN ASSOCIATION», 24 Leningradskaya St., 141400, M.O., Khimki, Russia \\ ${ }^{2}$ Rostov State University of Civil Engineering (RSUCE), 162 Sotsialisticheskaya St., 344022, Rostov-on-Don, Russia
}

\begin{abstract}
The present paper is aimed to study the conceptual feasibility of a fabrication of structures from the moon soil by selective sintering on a $3 \mathrm{D}$ printer by means of sun radiation. Establishment of a habitable Lunar base is a target mission of space agencies of the USA, Europe, China, Japan and India. Therefore, the search for possible methods of constructing the structures of different buildings on the Moon providing a minimum power consumption is of interest. The most preferable way of fabricating building materials would be the sintering of the moon soil by means of focused sun radiation. To realize it, it is necessary to develop a relevant technology in laboratory conditions using the simplest model soils. Special equipment has been developed with an artificial sun radiation and a high quality artificial moon soil. Sintering of the soil by radiation of a high power xenon gas discharge lamp with sapphire window has been carried out. As the artificial moon soil, a silica glass nanopowder has been used. The sintering has been carried out at different values of radiant flux density of the gas discharge lamp. The basic factor characterizing the production efficiency of technology is a time interval required for sintering a sample with a specified thickness. Another factor is the internal porosity of material obtained, which must be known to estimate the gas permeability and strength of future moon structures. The samples obtained have been studied in terms of porosity and strength. The results obtained have shown that 3D printing based on sintering by sun radiation to make building materials on the Moon is a promising method. The method developed can make a basis for the design a 3D printing equipment for future Lunar missions.
\end{abstract}

Keywords: 3D-print, sintering, moon soil, solar radiation.

\section{Моделирование спекания имитаторов лунного грунта солнечным излучением}

\author{
Багров А. В. ${ }^{1}$, Сысоев А. К. ${ }^{2}$, Сысоев В. К. ${ }^{1}$ Юдин А. Д. ${ }^{1, \dagger}$ \\ ${ }^{1}$ ФГУП НПО «им. С.А. Лавочкина», ул. Ленинградская 24, 141400, Химки, Россия \\ ${ }^{2}$ Академия строительства и архитектуры ДГТУ, ул. Социалистическая 162, 344022, Ростов-на-Дону, Россия
}

Работа посвящена изучению возможности изготовления строительных элементов из лунного грунта методом селективного спекания на 3D принтере с использованием солнечного излучения. Создание обитаемой лунной станции является целью многих космических агентств США, Европы, Китая, Японии и Индии. Поэтому актуальным является поиск возможных методов строительства конструкций различных сооружений на Луне с минимальными энергозатратами. Наиболее приемлемым вариантом получения строительных материалов является спекание лунной пыли сфокусированным излучением Солнца. Для этого необходимо на Земле отработать такую технологию в лабораторных условиях на простейших моделях грунта. Была создана установка с искусственным источником солнечного излучения и высокочистым имитатором лунного грунта. Моделировалось спекание имитаторов лунного грунта излучением мощной ксеноновой газоразрядной лампы с сапфировым окном. В качестве имитаторов лунного грунта использовались нанопорошки из кварцевого стекла. Моделировалось спекание имитатора лунного грунта при различной плотности мощности излучения газоразрядной лампы. Основным показателем такой методики была оценка времени, необходимого для спекания образцов определенной толщины, что определяет производительность данной технологии. Другой показатель - пористость полученного материала, параметр, который необходимо знать для оценки газопроницаемости будущих лунных сооружений и их относительной прочности. Были проведены исследования полученных образцов на пористость и прочность. Полученные результаты показывают перспективность использования 3D-печати методом спекания солнечным излучением для получения строительных материалов на Луне. Созданная методика может служить основой для проектирования 3D установки для будущих лунных экспедиций.

Ключевые слова: 3D-печать, спекание, лунный грунт, солнечное излучение. 


\section{1. Введение}

В настоящее время многие космические агентства США, Европы, Японии, Китая, Индии планируют создание исследовательских долговременных станций на Луне. Первым шагом этих исследований будет осуществление российского проекта посадочной станции «Луна-25» в 2019 году [1]. Поэтому актуальным является анализ возможных методов строительства конструкций различных сооружений на Луне и решение проблемы получения стройматериалов из лунного грунта [2].

Сооружение сложных конструкций на Луне ограничено материально-техническими и энергетическими ресурсами, которые можно доставлять космическими экспедициями с Земли. Поэтому использование природных лунных материалов является обязательным условием всех проектов капитального строительства на Луне.

При подготовке к строительству конструкции базы на Луне необходимо еще на Земле разработать технологию изготовления строительных блоков из лунного материала.

Наиболее перспективным представляется создание конструкций с помощью мобильного 3D принтера, в котором используется лунная пыль и солнечное излучение [2-5]. Такой подход позволит минимизировать энергетические затраты при лунном строительстве. На Земле этот подход был успешно апробирован при использовании песков Сахары и концентраторов солнечного излучения [6]. Поэтому моделирование спекания мелкодисперсных материалов - имитаторов лунного грунта под действием лабораторного имитатора солнечного излучения представляет значительный интерес.

\section{2. Методика моделирования}

Методика моделирования строилась на трех принципах.

Первый заключался в создании лабораторного источника со спектральной характеристикой излучения, максимально приближенной к спектру солнечного излучения и имеющей высокую плотность мощности излучения, близкую к параметрам реализуемые в солнечном $3 \mathrm{D}$-принтере в работе [6] $\sim 10^{3} \mathrm{~B} / \mathrm{cm}^{2}$.

Такой источник был создан на основе разборной металлической газоразрядной лампы. Излучение дугового разряда в атмосфере Хе при давлении 4 МПа фокусировалось с помощью сфероэллипсоидного отражателя в пятно $3 \div 7$ мм. Особенностью такого источника является использование сапфирового окна для вывода излучения, что позволяет максимально приблизить спектр излучения лампы к солнечному спектру.

Данный источник излучения показан на рис. 1.

Такой источник излучения позволил получить плотности мощности излучения порядка 5 кВт/ $\mathrm{cm}^{2}$ в пятне диаметром 0,5 см [7].

Второй принцип заключался в выборе материала имитатора лунного грунта. Как показано в работе [8], имеющиеся модельные аналоги лунного грунта отличаются большим разнообразием и его состав и распределение по размерам компонентов зависят от глубины залегания, но поверхностный слой содержит различные

минералы с большим содержанием $\mathrm{SiO}_{2}$ с преобладающими размерами $50 \div 100$ мкм. В нашей работе в качестве такого имитатора был выбран высокочистый нанопорошок аморфного кварцевого стекла, получаемый лазерным испарением $[9,10]$. Использование такого порошка позволяет проводить эксперименты с высокой повторяемостью. Характеристики такого порошка показаны на рис. 2.

Третий принцип заключается в изготовлении образцов имитаторов лунного грунта из кварцевых порошков

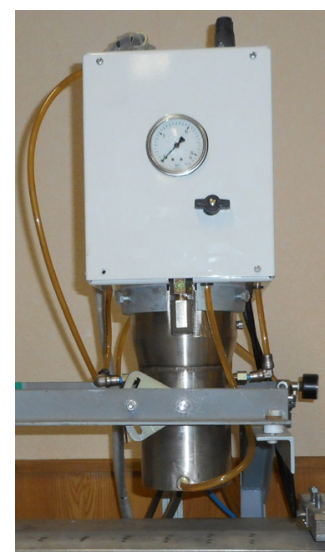

a

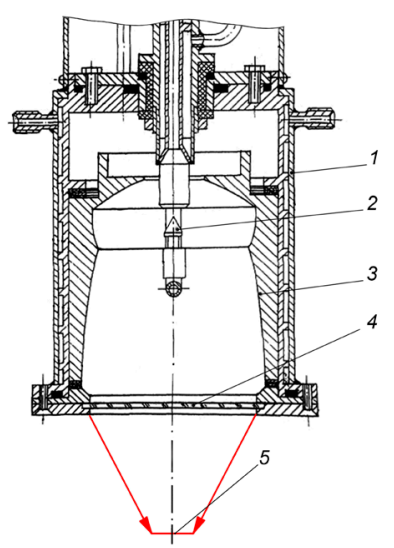

b

Рис. 1. Разборная металлическая ксеноновая лампа высокого давления: внешний вид (a), схема лампы (b); 1 - корпус, 2 - электрод, 3 - отражатель, 4 - сапфировое окно, 5 - зона сфокусированного излучения.

Fig. 1. Demountable metallic high pressure xenon lamp: external view (a), scheme of lamp (b); 1 - frame of the lamp, 2 - electrode, 3 - reflector, 4 - sapphire window, 5 - focusing radiation zone.

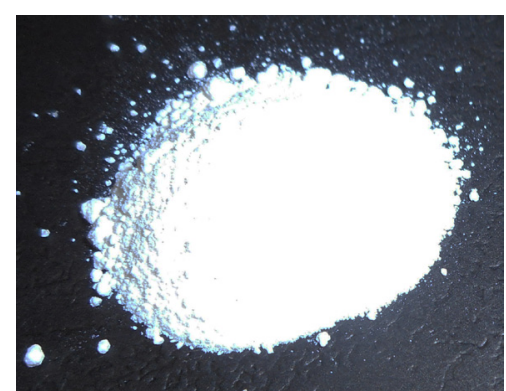

a

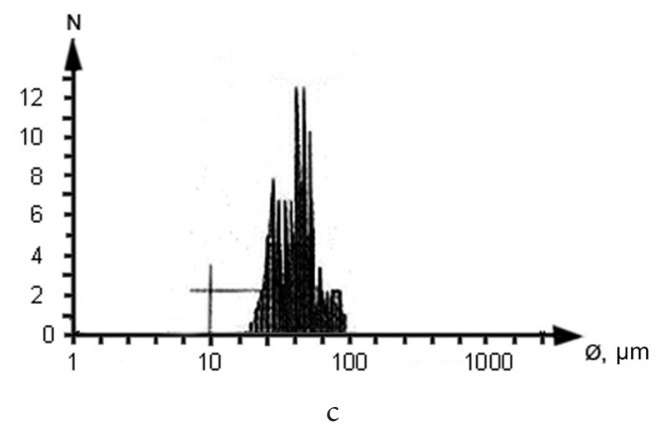

Рис. 2. Порошок $\mathrm{SiO}_{2}$, полученный лазерным испарением кварцевого стекла: общий вид (a), снимок с электронного микроскопа (b), гистограмма размеров (c).

Fig. 2. Silicon dioxide powder produced by laser evaporation of quartz glass: general view (a), electron microscopic image (b), histogram of size distribution (c). 
путем спекания порошка излучением газоразрядной лампы. При этом спекались образцы из порошков с различной весовой плотностью (т. е. порошки уплотнялись) и для каждой плотности порошка варьировалась плотность мощности излучения лампы.

Полученные керамические образцы подвергались испытаниям на пористость и прочность по схеме ассиметричного изгиба на кольцевой опоре до разрушения $[11,12]$.

\section{3. Результаты экспериментов}

Образцы получали в кюветах диаметром 10 мм и высотой не более 5 мм, партиями по 10 шт.

Первые образцы получали путем насыпания в кювету порошка без уплотнения, и плотность составляла 1,3 г/см ${ }^{3}$ что соответствовало плотности лунной пыли на поверхности Луны. Глубокое проплавление (на 5 мм) при плотности мощности излучения $300 \mathrm{BT} / \mathrm{cm}^{2}$ происходило в течение времени более 20 мин.

При уплотнении порошка до 2 г/ $\mathrm{cm}^{3}$ проплавление порошка на глубину 5 мм происходило гораздо раньше (через 5 мин), что показано на рис. За. Из этого следует, что в будущем лунном 3D солнечном принтере, необходимо иметь устройство для предварительного уплотнения лунной пыли перед спеканием.

Партия керамических образцов, полученных с различными весовыми плотностями и при различной плотности мощности излучения лампового источника при условии проплавления их на глубину 5 мм, подвергалась испытаниям на пористость и прочность. Результаты этих испытаний показаны на рис. $3 \mathrm{~b}$.

Представленные характеристики полученных керамических образцов имеют высокую повторяемость, что связано с однородностью использованного материала и стабильностью мощности излучения лампового источника.

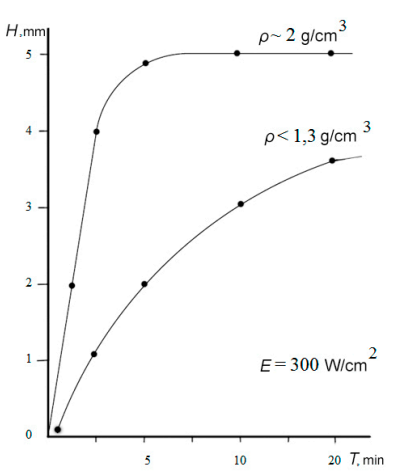

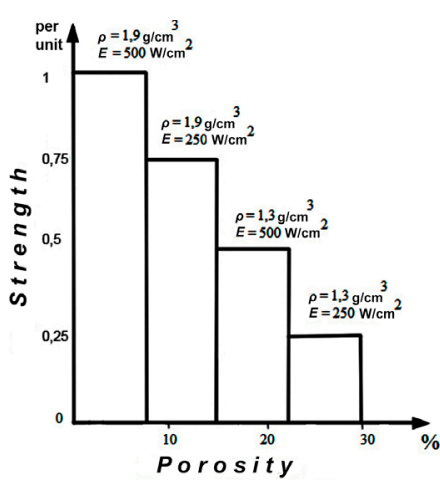

b
Рис. 3. Зависимость глубины проплавления порошка $\mathrm{SiO}$ от времени при различных исходных плотностях порошка (a), зависимость относительной прочности и пористости керамических образцов от весовой плотности порошка и плотности мощности излучения лампы (b).

Fig. 3. Dependence of fusion penetration depth of silicon dioxide powder on time for different initial powder densities (a), dependence of the relative strength and the relative porosity of the ceramic samples on weight powder density and output power density of lamp (b).

\section{4. Заключение}

Результатами данной работы является создание экспериментальной установки для моделирования спекания солнечным излучением имитаторов лунного грунта различного состава. На основе работ, на этой установке с различными по составу имитаторами лунного грунта, планируется создание 3D-принтера для отработки технологии лунного строительства.

Благодарность/Acknowledgements. Авторы выражают благодарность Папченко Б. П. за помощь в работе.

\section{Литература/References}

1. Мартынов М.Б., Москатиньев И. В., Казмерчук П. В., Сысоев В.К., Юдин А.Д. Космический аппарат «Луна-25» - основа новых исследований на Луне// Вестник НПО им. С. А. Лавочкина. 2016. №4. С. 9 - 19.

2. Багров А.В., Нестерин И.М., Пичхадзе К.М., Сысоев В.К., Сысоев А.К., Юдин А.Д. Анализ методов строительства конструкций лунных станций // Вестник НПО им. С. А. Лавочкина. 2014. № 4. C. $75-80$.

3. Цыганков О.С. Концептуальная модель формирования лунной исследовательской станции // Полёт. 2008. № 12. С. 8 - 12 .

4. Ксандопуло Г.И. Развитие новых технологий для использования ресурсов луны и марса // Космические исследования и технологии. 2013. № 1. С. $24-31$.

5. Даффи Дж. А., Бекман У.А. Тепловые процессы с использованием солнечной энергии. М.: Мир, 1977. $420 \mathrm{c}$.

6. http://www.markuskayser.com

7. Сысоев В. К, Лезвинский К. ЈІ., Вятлев П.А., Захарченко А.В., Булкин Ю.Н., Алексеев Г.М., Шилов С.С., Коновалов О.В. Увеличение эффективности мощного полихроматического светового источника излучения // Электронный научный журнал «ИССЛЕДОВАНО В РОССИИ». 2006. № 193. С. 1815-1824. (http://zhurnal.ape.relarn.rU/articles/2006/193.pdf)

8. Слюта Е.Н. Физико-механические свойства лунного грунта // Астрономический вестник. 2014. Т. 48. № 5. C. $358-382$.

9. Сысоев В.К., Русанов С.Я. Обработка кварцевого стекла излучением $\mathrm{CO}_{2}$ лазера // LAP Lambert Academic Publishing. 2012. 192 c.

10. Сысоев В. К, Русанов С.Я. Лазерный синтез нанопорошков диоксида кремния // Нанотехника. 2007. № 11. С. $71-78$.

11. Плаченое Г. Г. Порометрия. Л.: Химия. 1998. 177 с.

12. Игнатова А.В., Кудрявцев О.А., Сапожников С.Б. Экспериментальное исследование и численное моделирование упругих характеристик и прочности пористой керамики // Вестник Пермского национального исследовательского политехнического университета. Механика. - 2015. - № 4. - С. 121 - 137. DOI: $10.15593 /$ perm.mech/2015.4.08 